\title{
O PROCESSO INVESTIGATIVO-REFLEXIVO COMO PROPULSOR DA CONSTITUIÇÃO DOCENTE
}

\author{
THE INVESTIGATIVE-REFLECTIVE PROCESS AS A PROPELLER OF THE \\ TEACHING CONSTITUTION
}

DOI: http://dx.doi.org/10.23926/RPD.2526-2149.2019.v4.n2.p791-809.id480

\section{Janice Silvana \\ Novakowski Kierepka \\ Mestre em Educação nas \\ Ciências (UNIJUÍ) \\ Professora na Escola \\ Estadual Técnica Guaramano \\ (GM-RS) \\ janicekierepka@bol.com.br}

\section{Daniele Bremm}

Licenciatura em Ciências

Biológicas (UFFS)

bremmdaniele@gmail.com

\section{Roque Ismael da \\ Costa Güllich}

Doutor em Educação nas

Ciências (UNIJUÍ)

Professor Titular na

Universidade Federal da

Fronteira Sul (UFFS)

bioroque.girua@gmail.com
Resumo: O trabalho objetiva reconhecer o papel da reflexão e das narrativas no processo de constituição docente. Para tanto, foram analisados diários de formação de duas professoras de Ciências, que participam dos Ciclos Formativos em Ensino de Ciências e Matemática, projeto de extensão do Grupo de Estudos e Pesquisa em Ensino de Ciências e Matemática (GEPECIEM) da Universidade Federal da Fronteira Sul (UFFS) Campus Cerro Largo. Foi possível identificar avanços na formação dessas professoras à medida que se distinguem diferentes níveis de reflexão, o que vai gradativamente transformando teorias e práticas. Também foi possível identificar progressos ocorridos nas práticas pedagógicas, de uma perspectiva tradicional para a valorização da pesquisa em sala de aula, diversificando as metodologias empregadas, porém mantendo alguns aspectos da aula tradicional. As reflexões no diário de bordo propiciam a explicitação das concepções de docência, Ciência e de ensino de Ciências, o que implica um processo de transformação das teorias e práticas.

Palavras-chave: Ensino de Ciências; Narrativas; Diário de Formação; Investigação-ação.

\begin{abstract}
The paper aims to recognize the role of reflection and narratives in the process of teacher education. Therefore, we analyzed teaching journals of two Science teachers who are, participating of the Educational Cycle in Science and Mathematics Teaching, an extension project of a Group of Study and Research in Science and Mathematics Teaching (GEPECIEM) of the Universidade Federal da Fronteira Sul (UFFS) Campus Cerro Largo. It was possible to identify advances in these teachers' formation as different levels of thought are distinguished, which gradually transform theories and practices. It was also possible to identify progress in pedagogical practices from a traditional perspective towards the appreciation of classroom research, diversifying methodologies used, while maintaining some aspects of the traditional class. The thoughts in the logbook provide explanation of teaching conceptions, Science and science teaching, which implies a process of transformation of theories and practices.
\end{abstract}

Keywords: Science Teaching; Narratives; Teaching Journa; Research Action. 


\section{INTRODUÇÃO}

As pesquisas na área de educação vêm indicando um caminho que podemos classificar como inovador na formação de professores. A tendência atual é a valorização da formação de um profissional reflexivo, pela via da investigação-ação, princípio teórico para a constituição de processos de formação de professores (ALARCÃO, 2010; CARR; KEMMIS, 1988; CONTRERAS, 1994; ROSA, 2004; GÜLLICH, 2013). Defende-se a relevância da problematização da prática pelos professores como instrumento potencializador de formação docente (CARR; KEMMIS, 1988; ELLIOT, 2000; CONTRERAS, 1994; SCHÖN, 1992; NÓVOA, 1992; ZEICHNER, 2008; TRIPP, 2005; ROSA; SCHNETZLER, 2003, 2004; GARCÍA, 1992; IMBERNÓN, 2010; PORLÁN; MARTÍN, 2001; DORIGON; ROMANOWSKI, 2008; REIS, 2008; DOMINGUES, 2007; PIMENTA, 2005; GÓMEZ, 1992). Do processo de problematização incide a reflexão, determinante do reconhecimento e enfrentamento de problemas da prática. Apostamos na formação/constituição do professor através de um processo dialógico, que ocorre por meio da reflexão como categoria formativa (ALARCÃO, 2010; GÜLLICH, 2013).

As situações práticas às quais o professor irá se deparar não podem ser totalmente previstas, à medida que a sala de aula é uma situação complexa de inter-relação de sujeitos (TARDIF, 2002). O professor constrói saberes a partir da experiência (TARDIF, 2002), processo do qual participa a reflexão sobre a prática. O entendimento da sala de aula "na prática constitui o objeto de pesquisa do professor e sobre o qual se dá o seu autoaperfeiçoamento profissional” (MALDANER, 1998, p. 56).

A possibilidade de formação do hábito reflexivo, permitindo ao professor identificar-se como um profissional em constante autoformação (NÓVOA, 1998, p. 25) e num caminho de auto monitoramento, é primada no modelo da investigação-ação, como característica que principia uma guisa de reflexão formativa/constitutiva do sujeito professor (ALARCÃO, 2010). Vários autores propõem a importância da reflexão de práticas (CARR; KEMMIS, 1998; IBIAPINA, 2008; SHÖN, 1992; GÜLLICH, 2013; GARCÍA, 1992; ALARCÃO, 2010). Nesse sentido, García sugere a formação de "professores que venham a refletir sobre a sua prática, na expectativa de que a reflexão será um instrumento de desenvolvimento do pensamento e da ação" (1992, p. 60), com a reconstrução de teorias e práticas.

Portanto, considerando a necessidade de formar professores reflexivos e buscando entender a dinâmica do processo, apostamos no diário de formação como instrumento que pode facilitar a formação do hábito reflexivo, por meio da produção de narrativas de suas práticas 
individuais e coletivas. Outro aspecto importante a ser considerado é o contexto formativo, pois, estando imersos em um grupo de estudos e pesquisa que propicia formação num modelo colaborativo e compartilhado, os professores têm a possibilidade de desenvolver sua constituição em perspectiva de investigação-ação.

O diário de formação é um objeto de registro da história do educador. Este meio possibilita acompanhar a própria evolução no sentido de processo formativo como profissional da educação, bem como a narração reflexiva das experiências educacionais mais significativas possibilita a posterior leitura e reflexão do próprio processo formativo. Estas considerações se baseiam em Porlán e Martín (2001, p.19), que afirmam que o diário de formação é um "guia para reflexão sobre a prática, favorecendo a tomada de consciência do professor sobre seu processo de evolução e sobre seus modelos de referência".

O diálogo que pode emanar a partir do compartilhamento de práticas em um grupo colaborativo (IBIAPINA, 2008) é uma forma eficiente para o aprimoramento destas ações, podendo tornar-se formativo (KIEREPKA; GÜLLICH, 2014). Porlán e Martín (2001, p. 37 [grifos do autor]) sugerem que a "leitura e discussão dos diários de classe pode facilitar o descobrimento dos 'obstáculos internos', favorecendo a implantação progressiva de uma estratégia de reflexão conjunta sobre e para a ação".

Ao se desenvolver a capacidade de reflexão das realidades vivenciadas, o sujeito tornase mais crítico e autônomo, implicando autonomia profissional, que se caracteriza pela não adoção do discurso educacional e do manual didático. Estas são duas temáticas que estão no cerne das questões formativas que envolvem professores, a autonomia e o livro didático, neste texto acenamos para estas categorias, embora não seja o foco de nossa discussão. Acreditamos que, à medida que desenvolvemos o processo de formação pela via da investigação-ação, o professor torna-se mais crítico e assim reconhece que práticas mais dinâmicas podem gradativamente substituir a cópia fiel dos livros de Ciências, o que caracteriza o ensino livresco desta área, já descrito pela literatura e que vem sendo investigado (KRASILCHIK, 2004; FRACALANZA, 2006; GÜLLICH, 2013).

$O$ presente trabalho tem a finalidade de compreender o potencial da reflexão como parte do processo de constituição docente, por meio da escrita de narrativas em diários de formação de professores de Ciências da Educação Básica, que participam de um processo de formação continuada que é mediado num grupo colaborativo e compartilhado de sujeitos professores. Por meio das narrativas, buscamos também entender o processo de avanço nos níveis de reflexão, que entendemos ser um processo gradativo, progressivo e constitutivo da docência em Ciências. 
O trabalho tem como enfoque a análise de um processo de constituição docente, especialmente tentando compreender como a reflexão progride por meio do desenvolvimento de narrativas, que tem como elemento metodológico o diário de formação. Defendemos que esse mecanismo permite ao sujeito professor em formação o desenvolvimento do hábito reflexivo na prática docente, desencadeando uma reflexão sobre as práticas, daí sistematização/pesquisa da própria prática, a típica e autêntica investigação-ação.

\section{Metodologia}

A investigação presente neste artigo contempla uma abordagem qualitativa de pesquisa, e é do tipo pesquisa narrativa, sendo que os procedimentos de análise e produção dos resultados ocorreram em três etapas, a saber: pré-análise, exploração do material e o tratamento dos resultados e interpretação (LÜDKE; ANDRÉ, 2001). A pesquisa em questão abrange um campo empírico situado nos Ciclos Formativos em Ensino de Ciências e Matemática, projeto de extensão do Grupo de Estudos e Pesquisa em Ensino de Ciências e Matemática (GEPECIEM), da Universidade Federal da Fronteira Sul (UFFS), Campus Cerro Largo/RS.

Para tanto, foram analisados dois diários de formação de professores de Ciências do Ensino Fundamental da rede pública de Cerro Largo/RS, que participam dos Ciclos Formativos, processo de formação continuada e compartilhada. Participam do grupo licenciandos dos Cursos da Área de Ciências, Biologia, Física e Química, da Universidade Federal da Fronteira Sul (UFFS), professores da Educação Básica, pública e privada, de Cerro Largo/RS e professores formadores da Universidade, em caráter de formação contínua, estruturando-se em uma tríade interativa (ZANON, 2003). Todos são considerados professores em formação que partilham um processo de investigação-ação de modo colaborativo (IBIAPINA, 2008), como sujeitos envolvidos que participam ativamente de um processo de formação coletivo.

Destacamos a investigação-ação como a mola propulsora na constituição docente, em que o diário de formação é um instrumento de registro e de narração do processo, com o intuito de se promover a reflexão crítica das práticas pedagógicas, sua devida sistematização. Inicialmente, foi realizada a leitura dos diários de formação; logo após, procedemos com a seleção, a demarcação e a digitação de trechos das narrativas, os quais foram analisados e categorizados a partir da análise temática dos conteúdos, conforme Lüdke e André (2001), tendo como referência os níveis de reflexão descritos por Porlán e Martín (2001) em correlação com o conceito de reflexão proposto por García (1992). Assim, foi possível identificar indícios, marcas, palavras e movimentos discursivos que contingenciam/emergem da análise e 
apresentam a reflexão como categoria de formação, de pesquisa e de melhoria das práticas, o que implica constituição docente.

Muitas das reflexões que analisamos se deram fundamentadas nas reflexões críticas colaborativas iniciadas/alavancadas no coletivo dos Ciclos Formativos e que proporcionou o confronto de ideias e práticas, que foram reelaboradas particularmente por cada indivíduo em suas narrativas em diários de formação, com a possibilidade de formação do hábito reflexivo.

$\mathrm{Na}$ produção/construção dos resultados desta investigação foram resguardados os princípios éticos da pesquisa, sendo devidamente autorizada por Comitê de Ética em Pesquisa. Nesse sentido, fizemos uso do termo de consentimento livre e esclarecido e os sujeitos foram nomeados como Professora 1 e Professora 2, garantindo assim o sigilo e anonimato aos sujeitos da pesquisa.

\section{Resultados}

\subsection{A REFLEXÃO DA AÇÃO DOCENTE COMO PROCESSO FORMATIVO INVESTIGATIVO}

O diário de formação é um objeto de registro da história do educador, por meio do qual este descreve suas vivências numa perspectiva de avanço para a transformação da prática, mesmo que a princípio não tenha essa intenção explicitada (PORLÁN; MARTín, 2001). As teorias pedagógicas servem como um subsídio para o confronto de teorias e enriquecem as reflexões, porém estas são relevantes quando interpretadas a partir da experiência prática. Segundo Álvarez e Marato (2013, p. 35), o principal objetivo da Investigação-Ação (IA) é "melhorar a prática e superar o estado de alienação do professorado, resolvendo problemas e demandas dessa prática, em vez de gerar conhecimento em sentido acadêmico". Para isso, é importante que a investigação priorize as relações colaborativas que se desenvolvem entre investigadores e professores.

Em grupos colaborativos (IBIAPINA, 2008) ocorre um favorecimento do processo de reelaboração de teorias e práticas em ambiente e contexto formativo. Nesse sentido, o diário de formação, por meio da reflexão escrita, garante que práticas sejam descritas e analisadas a partir de reflexões coletivas. Por este processo, o professor (re)constrói a sua própria teoria pedagógica de forma autônoma, tornando-a crítica e investigativa. O professor, ao investigar sua própria prática, pode "tomar consciência de sua concepção de educação e, a partir disto, planejar caminhos que lhe permitam preservar sua autonomia profissional" (ROSA, 2004, p. $56)$. 
O professor precisa se tornar um profissional reflexivo para poder envolver o aluno na reflexão, formando sujeitos com capacidade intelectual crítica. Segundo Alarcão (2010, p. 44), “a noção de professor reflexivo baseia-se na consciência da capacidade de pensamento e reflexão que caracteriza o ser humano como criativo e não como mero reprodutor de ideias e práticas que lhe são exteriores”. Um professor reflexivo compõe sua atuação com base na ciência, técnica e precisa de ter sensibilidade sobre as situações (SHÖN, 1983, 1987). A formação de professores, inicial e continuada, pode formar docentes investigadores, críticos e reflexivos. Para tanto, deve ocorrer "através de um trabalho de reflexividade crítica sobre as práticas e de reconstrução permanente de uma identidade pessoal" (NÓVOA, 1995, p. 25). Por isso, é importante a participação em grupos colaborativos, em que seja priorizada a reflexão conjunta, além da reflexão pessoal no diário de formação. Quem salienta isso também é Filho et al. (2018, p. 770):

[...] a construção do saber deve se dar a partir da mediação e da reflexão constante destes profissionais sobre a sua própria prática. Isso implica compreender a ação educativa para além da técnica, considerando, dentre outros aspectos, a subjetividade decorrente dos atores envolvidos no processo.

A partir da análise dos diários de formação, destacamos um trecho que contém indícios de reflexão sobre uma prática: “[...] além de despertar a curiosidade para o assunto, também vem promover a interação em grupo, especialmente a capacidade de cooperação, organização e coordenação. Estimula a observação e a pesquisa" (Professora 2). Pode-se perceber a ressalva à importância da interação em sala de aula. Castanho e Costa (1999, p. 109) afirmam que Vigotski, bem como Luria e Leontiev, defendem o sócio-interacionismo, “consolidando-se a noção de que o indivíduo aprende na interação com os parceiros. Todo conhecimento é conhecimento partilhado". Por isso, a importância de desenvolver práticas de ensino que promovam o diálogo e discussão entre os sujeitos. Além disso, é importante destacar no excerto anterior a relevância concedida à pesquisa, no fragmento "Estimula a observação e a pesquisa" (Professora 2). Vários autores (DEMO, 2000; MORAES, 2002; MORAES; GALIAZZI; RAMOS, 2002; GALIAZZI; 2003) defendem o educar pela pesquisa no ensino.

As considerações realizadas pela Professora 2 sobre a importância da interação e da pesquisa são indícios do reconhecimento de práticas e teorias, possibilitado provavelmente por leituras, discussões e reflexões realizadas nos Ciclos Formativos. Exemplificando com o excerto anterior, queremos destacar a importância da reflexão sobre a própria ação, com a possibilidade de reconhecimento de teorias e práticas, assim como a sua reconstrução, por meio da reflexão, que gere um replanejamento e nova ação. Rosa (2004, p. 34) propõe o 
desenvolvimento de espirais autorreflexivas, com as etapas: "explicitação de problema prático; análise do problema e planejamento; ação; observação; reflexão; replanejamento; nova ação". A reflexão é assumida como uma das etapas da espiral e é a base para o planejamento de novas intervenções.

Demo (2000) sugere que o educar pela pesquisa também serve para orientar a pesquisa do professor sobre sua própria prática, em aproximação ao princípio da investigação-ação. Assim, o professor se constitui constantemente. "A formação continuada é o tempo da reflexão da sua prática e prevê um planejamento centrado na investigação da realidade da vida e no conteúdo da matéria com que está trabalhando. É a reflexão da sua prática, realizada de modo contínuo" (CALLAI, 1998, p. 70). O professor pode se reconhecer como um profissional em constante formação, tanto em questões conceituais como em relação à teoria pedagógica, que se torna significativa ao ser (re)interpretada pelo próprio professor.

À medida que nos propomos a compreender a investigação-ação como modelo de formação docente, torna-se relevante analisar como ocorre o processo de desenvolvimento das narrativas em termos de níveis de reflexão, pois esse desenvolvimento demarca a investigaçãoação em si, ou seja, a pesquisa da própria prática, que, à medida que avança, pode demonstrar cada vez níveis mais efetivos de reflexão. No início, as narrativas caracterizam-se como uma forma descritiva, evoluindo, gradativamente, para os níveis analítico-explicativo e posteriormente valorativo (reflexivo propriamente dito) como o nível mais profundo e formativo, segundo Porlán e Martín (2001).

O primeiro nível de reflexão, o descritivo, é caracterizado pela narração das aulas, ou seja, são apenas descrições. A escrita do diário tem uma visão simplificada da realidade e não se consegue estabelecer relações entre os diferentes elementos. Conforme Porlán e Martín (2001, p. 21), "esta percepção simplificadora conduz a que o diário se centre inicialmente em aspectos superficiais da realidade, esquecendo-se de outros menos evidentes", que podem ser exemplificados em variáveis do contexto que influenciam na aprendizagem do aluno, porém não são destacados, apenas atribuindo padrões de comportamento à personalidade do aluno.

Com a finalidade de exemplificar esse nível inicial, transcrevemos um excerto da narrativa do diário de formação da Professora 1. Percebemos que esta professora descreve os tipos e sequências das atividades, bem como o contexto da aula, descrevendo o ambiente de trabalho como difícil e empreendendo uma análise simples e comportamentalista, como segue:

[...] para os alunos sem prova, determinei que fizessem um texto sobre as páginas 20 até 49 , eles não gostaram da atividade. Depois, no segundo período, fiz uma revisão 
sobre as bactérias. Apliquei um questionário sobre a classificação dos seres vivos, vírus e bactérias. [...] É difícil o trabalho com os alunos, eles tem muita facilidade para a dispersão. Tudo é ruim para alguns alunos. [...] Estou preocupada com a turma, não estou conseguindo empolgá-los para o estudo das ciências (Professora 1).

Portanto, no início da escrita do seu diário de formação a professora demonstra estar no nível descritivo, principiando a reflexão. O objetivo "nesta fase deve centrar-se em oferecer inicialmente um panorama geral e significativo do que, do nosso ponto de vista, acontece na sala de aula, descrevendo as atividades, relatando processos" (PORLÁN; MARTÍN, 2001, p. 24). O que se percebe no excerto anterior é a descrição dos procedimentos utilizados na aula, além da análise do comportamento dos alunos, porém não há evidências de reflexão sobre causas, consequências ou alternativas para a melhoria de comportamento.

Com o tempo, mediação da formação, hábito de escrever, a escrita narrativa tende a progredir diferentemente e:

há de propiciar [...] o desenvolvimento de um nível mais profundo de descrição da dinâmica da aula a través do relato sistemático e pormenorizado dos distintos acontecimentos e situações cotidianas. O próprio fato de refletir por escrito favorece o desenvolvimento de habilidades de observação e categorização da realidade, que lhe permitem ir além da simples percepção intuitiva (PORLÁN; MARTÍN, 2001, p.22).

A tendência com o tempo é a reflexão evoluir do nível apenas descritivo para o nível analítico-explicativo, em que a descrição não desaparece, pois na narrativa é importante conhecer o contexto, porém vai além da simples descrição, priorizando também a análise. Mas, é difícil diferenciar a descrição de interpretações e valorações espontâneas, o que pode ser superado na medida em que se vai incorporando uma diferenciação consciente entre o que se descreve espontaneamente e a análise posterior ou paralela que se pode fazer. Desta forma, começam a surgir os problemas na prática e os dilemas conceituais, “[...] o desenvolvimento de um nível mais profundo de descrição da dinâmica da aula através do relato sistemático e pormenorizado dos distintos acontecimentos e situações [...] que lhe permitem ir além da simples percepção intuitiva" (PORLÁN; MARTÍN, 2001, p.22). Assim vão sendo, pois, constituídos os problemas práticos de investigação do professor, o que pode indicar um modelo de pesquisa para o professor que atento ao seu processo de formação e pesquisa da sua própria prática.

"As narrativas serão tanto mais ricas quanto mais elementos significativos se registrarem" (ALARCÃO, 2010, p. 57). A despeito deste nível (explicativo-analítico), no diário da Professora 2, podemos exemplificar com uma narrativa em que a reflexão tende a migrar para uma análise ou explicação: “[...] por isso da importância de relacionar teoria e prática para 
um maior êxito na aprendizagem". Para além de descrição, a professora explica a importância de integrar teoria e prática, por meio do desenvolvimento de práticas experimentais.

Podemos perceber, que à medida que a professora 2 avança seu nível de reflexão para o explicativo, ela não deixa de lado a descrição, pois as reflexões são cumulativas, sendo a descrição dos fatos necessárias para que na sequência ela possa analisar o que acabou de descrever para avançar no caminho de transformação de sua prática/melhoria da ação (CARR; KEMMIS, 1988). Da mesma forma, ao avançar para o nível mais elevado crítico-reflexivo, não deixamos para trás as características dos outros níveis de reflexão, descrição e explicação, mas utilizamos delas como propulsão para em seguida nos questionarmos e refletirmos criticamente sobre os fatos, problemas pedagógicos, teorias e concepções.

Assim, a escrita no diário de formação possibilita o reconhecimento de problemas na prática docente e o aprofundamento da compreensão da dinâmica que envolve a aula em si e as questões de ensino e de aprendizagem que vão se reformulando durante o processo de investigação, pois "o ato da escrita é um encontro conosco e com o mundo que nos cerca" (ALARCÃO, 2010, p. 57).

De acordo com Porlán e Martín (2001, p. 26), “o diário de formação facilita a possibilidade de reconhecer esses problemas e de assumir a realidade escolar como complexa e em constante transformação, favorecendo seu tratamento através da análise dos mesmos”. A problematização da prática possibilita o reconhecimento e questionamento de concepções que orientam a prática, pois à medida que vão sendo explicitadas as teorias implícitas no fazer docente, também vão sendo apreendidos saberes da docência e as chances de melhoria da prática vão aumentando gradativamente, põem-se em movimento as teorias e o fazer através da análise do pensamento e contexto real.

A partir do nível analítico-explicativo, a tendência das narrativas é evoluírem para um terceiro nível, mais valorativo e reflexivo propriamente dito. Podemos perceber que as professoras investigadas estão num momento de transição do nível descritivo para o analíticoexplicativo, porém já podemos identificar alguns indícios de um nível mais evoluído de reflexão, nas marcas do texto, momento em que a professora após relatar um processo de ensino conturbado com falta de atenção dos alunos, reflete - percebe que a aula dela está tradicional, o que a faz colocar em movimento suas estratégias. Em sua narrativa, a professora descreve:

estou realizando poucas atividades com eles. Os alunos são muito dispersivos, perdem logo o interesse, há pouca empolgação, estão preocupados ou interessados em outras coisas, não de ciências. Está difícil trabalhar com essa turma. Estou muito tradicional - lendo - perguntando - perguntas e resposta (Professora 1). 
Adquirir o hábito reflexivo é muito difícil, diante de uma folha de papel em branco, ficamos a nos perguntar o que escrever. Alarcão (2010, p.57) nos ajuda com várias perguntas que irão induzir ao primeiro nível de reflexão, o descritivo, sendo elas: "o que aconteceu? Como? Onde? Por quê? O que senti?" e ao final indica uma pergunta que pode nos ajudar a avançar nesta reflexão "o que penso sobre o que aconteceu?”.

A passagem do nível descritivo para um nível mais avançado, onde se buscam interpretações e justificativas para os fatos, é em geral um processo lento, mas que pode variar de pessoa para pessoa, estando muito ligado, segundo Alarcão (2010), à vontade, persistência, sistematização e a elaboração de relações. Pois "a reflexão para ser eficaz precisa ser sistemática nas suas interrogações e estruturante nos saberes dela resultantes" (ALARCÃO, 2010, p. 50). Ainda segundo Alarcão (2010), a sistematização precisa seguir um triplo diálogo: consigo mesmo, com os outros e com a situação como um todo.

Portanto, o desenvolvimento dos níveis de reflexão é gradual, tende a ser progressivo e parece se desenvolver a partir da prática de escrita no diário de formação, que também conta com as discussões em contextos colaborativos de formação. A reflexão é tomada como uma estratégia de formação e investigação, ou seja, a categoria formativa vai sendo desenvolvida gradativamente pelos sujeitos envolvidos no processo de investigação-ação.

\subsection{UMA INTERVENÇÃo: A GRADATIVA TRANSFORMAÇÃo dA PRÁtiCA POR MEIO do PROCESSO REFLEXIVO}

O processo de intervenção é compreendido por Güllich (2013 p. 219) como a transformações das práticas. Para ele, “a intervenção pressupõe transformação, melhoria da ação, qualificação da formação, das práticas, da educação, da sociedade”. Já o movimento de reflexão, que ocorre à medida que os problemas são colocados em pauta, é denominado de démarche e está diretamente relacionado à intervenção. Esta é possibilitada através do movimento reflexivo da ressignificação que ocorre na espiral autorreflexiva, culminando em transformação das práticas: intervenção (CARR; KEMMIS, 1988). A formação de professores, apoiada na IA, pode provocar mudanças, é neste sentido que "a IA se coloca para além de uma metodologia de pesquisa ou de ação, pois é compreendida como concepção de intervenção" (GÜLLICH, 2013 p. 230).

As reflexões no diário de formação, aliado às reflexões compartilhadas em coletivos de formação, podem propiciar um avanço no sentido de inovação nas práticas pedagógicas e a consequente melhoria destas. Professores que participam de contextos colaborativos de 
formação têm a reflexão como mola propulsora de transformação de teorias e práticas, colaborando para a superação de métodos mais tradicionais, que no caso analisado passam de práticas mais livrescas para práticas em que percebemos manifestações de elementos do educar pela pesquisa. Os dados são um mosaico e, para serem interpretados em suas múltiplas facetas, precisam ser olhados por diversas perspectivas. Desta forma, anteriormente analisamos os níveis de reflexão de acordo com Porlán e Martín (2001), e agora analisaremos a transformação da prática pela via da reflexão, com base nos mesmos indícios, ou seja, olhando para as mesmas narrativas, porém sob outro viés.

A superação do ensino tradicional nas escolas é necessária para que seja criada outra lógica no processo de aprendizagem, abrindo espaço para o aluno se posicionar como sujeito da produção de sua própria aprendizagem, transformando o contexto da sala de aula e a produção de conhecimento. Para isso, mudam-se as relações em sala de aula, em que o professor passa a ser mediador do ensino e o aluno agente ativo em sua aprendizagem. Adotar o modelo de aula fundado numa perspectiva investigativa é desafiante ao professor, que precisará se adequar, partindo de transmissor para mediador da aprendizagem. A mediação do ensino pode se efetuar por "diferentes estratégias e recursos. [...] principalmente pelo incentivo à pesquisa, o planejamento de projetos e sua concretização" (MORAES, 2004, p. 22).

$\mathrm{O}$ aluno precisa ser instruído para a reflexão, o que acarreta a necessidade de o professor constituir-se também como um profissional reflexivo, uma vez que se tornam necessárias novas competências. Portanto, a superação do ensino tradicional exige dedicação por parte dos professores, bem como políticas públicas que possibilitem principalmente a participação dos professores em contextos diferenciados de formação colaborativos. Segundo destaca Maldaner (1998, p. 57), "a formação continuada na prática, mediada pelas teorias e em confronto com os seus pares, é entendida como necessidade fundante da constituição de professores capazes de proporcionar educação melhor", pois pela via da discussão reflexiva e dialógica podem os professores avançar em seu autoconhecimento e ação.

Com o intuito de compreender a dinâmica processual que se dá na ação docente, quando os professores tentam migrar de uma perspectiva de ensino mais tradicional para uma mais contextual ou reflexiva, buscamos analisar as narrativas dos sujeitos da pesquisa.

Analisando o processo formativo de uma professora, constatamos que o ensino está pautado por uma perspectiva tradicional, como é possível perceber no excerto abaixo, extraído do diário de formação no início de sua escrita: 
[...] logo após passei a fazer um exercício sobre os vírus. Passei um texto sobre o reino monera e fiz algumas explicações. Os alunos usaram as fichas para o baú da memória. Logo em seguida fizemos uma leitura na apostila sobre as bactérias e os alunos anotavam a importância das bactérias no caderno (Professora 1).

Podemos perceber que, no excerto citado da Professora 1, a mesma concebe o ensino como transmissão de conhecimentos, onde ela é a detentora do conhecimento e transmite o mesmo para os alunos, no caso através de propostas de leitura. Em momento algum ela atua através de questionamentos de forma a intencionar um processo de investigação e que desenvolva a autonomia dos alunos sobre a sua aprendizagem. Segundo Rosa e Schnetzler (2003), os professores que compreendem o ensino de forma tradicional, através da transmissão de conhecimentos, concebem a investigação educativa pelo modelo da racionalidade técnica. Segundo este modelo, "a atividade profissional consiste na solução instrumental de um problema feita pela rigorosa aplicação de uma teoria científica ou uma técnica" (SCHÖN 1983, p. 21), não levando em conta os conhecimentos prévios dos alunos e os conceitos que eles trazem do seu dia a dia.

Nesta concepção tradicional de ensino está implícita "a crença da simplicidade do ato pedagógico. Simplicidade que se configura na transmissão de conteúdos por parte do professor e sua recepção diligente e passiva por parte do aluno" (MALDANER, 1998, p. 56). Essa crença é muito disseminada popularmente e de certa forma acarreta a desvalorização da profissão do professor, o qual precisa agir na perspectiva de mudança, iniciando pela sua sala de aula. Pois, se o professor apenas se detém ao uso do manual didático, acaba por reforçar essa convicção de docência simplista, ao tomar a prática pedagógica como um ato simples.

Devemos destacar que as professoras em questão fazem uso do diário de formação como instrumento de reflexão desde o ano de 2010, fazendo, portanto, em torno de seis anos que se utilizam desta ferramenta. Assim, as narrativas dos diários de formação nos fazem notar a progressão no decorrer das reflexões que tendem a evoluir, conforme destacado anteriormente, bem como, algum tempo depois, percebemos avanços quando a mesma professora se mostra consciente de que suas práticas são muito tradicionais:

Estou realizando poucas atividades com eles. Os alunos são muito dispersivos, perdem logo o interesse, há pouca empolgação, estão preocupados ou interessados em outras coisas, não de ciências. Está difícil trabalhar com essa turma. Estou muito tradicional - lendo - perguntando - perguntas e resposta (Professora 1).

Portanto, aqui a reflexão no diário de formação está colaborando para perceber melhor as teorias que guiam as suas aulas e quiçá para tomada de consciência dos seus saberes e fazeres. Através da reflexão de suas práticas no diário de formação, o professor explicita suas crenças, 
teorias, sentimentos, concepções de ensino e conhecimento, que, às vezes inconscientemente, influenciam as práticas pedagógicas. Além disso, "ajuda também a projetar hipóteses de intervenção que tentam resolver estes problemas a partir de novas perspectivas. A investigação de problemas implica a experimentação de novos projetos e avaliação de seus efeitos" (PORLÁN; MARTÍN, 2001, p.18).

Consideramos que a narrativa da Professora 1 contenha indícios de um processo inicial, mas propulsor de transformação de sua prática, que inicia, neste caso, com a explicitação das teorias guiando-se e deve progredir pela reflexão mais amadurecida no diário de formação. Aqui ressaltamos também a relevância de contextos formativos de discussão e confronto de teorias e hipóteses, possibilitando reconhecimento coletivo, discussões efetivas de práticas que migram gradativamente para reflexões individuais, produzindo conhecimento profissional e melhoria das práticas do professor em questão.

Portanto, neste caso, a reflexão está contribuindo para a professora se (re) conhecer como um profissional que pode modificar a sua prática. Assim, percebemos também que outra professora, que faz uso do diário de formação, também avança no caminho da transformação das práticas. Ao analisar sua narrativa, percebemos que ela começa a incorporar à sua prática elementos do educar pela pesquisa, ou seja, a pesquisa vai gradativamente sendo assumida nas salas de aula das escolas como uma possibilidade na contracorrente da aula livresca e tradicional:

[...] após a teoria [...] partimos para a prática. [...] esta técnica além de despertar a curiosidade para o assunto, também vem promover a interação em grupo, especialmente a capacidade de cooperação, organização e coordenação. Estimula a observação e a pesquisa [...] a aula foi dinâmica e divertida, pois os alunos, além de interagirem, trocaram ideias, questionamentos e refletiram sobre a importância de conhecer e registrar as diferentes espécies de seres vivos existentes na terra (Professora 2).

À medida que a professora desenvolve práticas experimentais, entre outras dinâmicas que envolvem pesquisa e produção de conhecimentos em aula, verificamos uma superação em relação ao uso do livro didático de forma excessiva. Estão presentes na descrição da ação docente elementos do educar pela pesquisa, como: valorização da sistematização escrita, do questionamento, da reflexão e da observação, o que indicia uma tentativa de instaurar uma nova e diferente prática de ensino (pela via da pesquisa), o que principia um caminho de transformação das práticas.

Podemos perceber que houve avanço no sentido da racionalidade prática, em que a professora já concebe o ensino como um processo mais complexo (ROSA; SCHNETZLER, 
2003), pois ela sai da sua zona de conforto e busca despertar nos alunos questionamentos e reflexão, demonstrando compreender a importância dos mesmos para o processo de aprendizagem dos alunos. Quando o professor apresenta em suas falas a racionalidade prática, percebemos que ele já avançou no seu nível de reflexão, sendo o mesmo definido como nível analítico-explicativo (caso da Professora 2, mencionada acima).

O conhecimento profissional dentro dessa visão não consiste em projetar um conjunto
de objetivos sequenciados e técnicas as quais "dirigem" os aprendizes para os
resultados da aprendizagem esperada. Ele consiste da direção e redireção espontânea
e flexível do processo da aprendizagem, guiada por uma leitura sensível das mudanças
sutis e da reação de outros participantes desse processo (CARR; KEMMIS, 1986, p.
37).

Analisando os excertos, percebemos que as professoras estão em uma transição do nível descritivo para o analítico-explicativo. Portanto, o nível mais avançado de reflexão, dito críticovalorativo, não se apresentou nos excertos das professoras, é o nível em que "[...] começam a surgir dilemas práticos e conceituais sobre os temas que mais nos preocupam e condicionam. À medida que se diferenciam os incidentes, avaliações e interpretações, os núcleos do problema estão se formando" (PORLÁN; MARTÍN, 2001, p. 31). Ademais, neste nível, a racionalidade que predomina é a crítica, pois a aprendizagem é alcançada quando o professor atua como mediador dos significados e questionamentos, que emergem das falas dos alunos durante as aulas, de forma a construir o conhecimento com eles (FREIRE, 1998).

Assim, é valorizado o educar pela pesquisa, fundamentado sobremaneira na reflexão do aluno, numa perspectiva construtivista de produção do conhecimento e não mais tradicional, baseada em geral na cópia do livro didático. Este caminho de transformações das práticas vai sendo trilhado pelo professor, que começa a compreender o seu conhecimento prático, pela pesquisa de sua ação, ou seja, participa ativamente de um processo de formação e efetiva uma investigação-ação em seu cotidiano; nisso incide a intervenção, em que a reflexão guia o processo. Importante ressaltar que o contexto de formação em que estão imersos os sujeitos da pesquisa contribui fortemente para que haja possibilidades de reconhecimento coletivo e colaborativo no que se refere à investigação-ação.

Portanto, ressaltamos o papel da escrita de narrativas no diário de formação, que contribui para o desenvolvimento dos níveis de reflexão (PORLÁN; MARTÍN, 2001). Contribui também para a percepção por parte do professor de que sua prática está fundamentada em teorias que podem ser transformadas, e este processo se inicia pela sua explicitação. $\mathrm{O}$ professor se reconhece como sujeito de seu processo de ensino, como autor de sua prática, percebendo que sua ação pode ser modificada, o que pode levar à superação do tradicional, do 
pronto, do copiado e acabado, abrindo margem para a inovação curricular, crescimento e desenvolvimento profissional.

Ressaltamos também a importância da sistematização das experiências narradas no diário de formação, momento de reflexão coletiva em que o professor pode se enxergar no outro, gerando círculos reflexivos de co-produção de conhecimentos, pois "o sujeito se constitui na interação com o outro" (VIGOTSKY, 2001). Ainda segundo Güllich (2013, p. 164), “o coletivo impõem a discussão e o diálogo que, ao meu ver, são os embriões da reflexão, não qualquer reflexão, uma reflexão formativa”. Nisso consiste a ideia e defesa de Alrcão (2010) e Güllich (2013) do conceito de Investigação-Formação-Ação (IFA).

A reflexão que ocorre durante os encontros dos Ciclos Formativos do GEPECIEM possibilita a constituição docente dos professores, ampliando o modelo de IA como modelo de formação IFA (GÜLLICH, 2013). Assim, podemos inferir que a escrita de narrativas nos Diários de Formação e a participação dos Ciclos Formativos do GEPECIEM permitem um processo de avanço em relação aos conceitos e aos níveis de reflexão dos professores participantes, em especial das professoras analisadas no artigo em questão. A intervenção, neste sentido, ocorre por meio do diálogo formativo e do movimento reflexivo que este induz, uma vez que o coletivo permite a sistematização das escritas, momento crucial para que as práticas, antes refletidas individualmente, nos diários de formação, agora sejam pensadas no coletivo, gerando um processo (no coletivo docentes), em que a investigação das ações (pesquisa da própria prática) é um momento (espaço-tempo) de formação.

\section{CONSIDERAÇões FinAIS}

O diário de formação é um instrumento de reflexão que está contribuindo para o desenvolvimento dos sujeitos da pesquisa como profissionais autônomos, reflexivos e críticos. Ao passo que o utilizam, tomam consciência de sua prática, o que implica certa transformação pela via da reflexão, que denominamos intervenção.

Percebemos que a prática da reflexão está avançando gradativamente e que os níveis de reflexão estão progredindo e parecem estar em transição do nível descritivo para o nível analítico-explicativo, e é possível identificar indícios do nível mais avançado, denominado valorativo ou reflexivo propriamente dito. Também é possível inferir que com o desenvolvimento das narrativas avança também a constituição docente numa perspectiva mais reflexiva e crítica. 
Analisando as aulas descritas pelas professoras no diário de formação, identificamos que estas, na sua maioria, estão marcadas pela concepção tradicional de ensino, com o forte uso do livro didático. Porém, percebemos que, à medida que é desenvolvida a prática da descrição no diário, pela via da reflexão, as práticas vão sendo transformadas. Percebemos que, aos poucos, ocorre a tomada de consciência sobre o processo didático, o que influencia na mudança das aulas. Concomitantemente às aulas tradicionais, as professoras vão incorporando aspectos inovadores da prática profissional.

Gradativamente, foram sendo identificados aspectos que demarcam práticas pedagógicas mais contemporâneas, fundamentadas no educar pela pesquisa e na experimentação, pois vão sendo valorizadas aulas desenvolvidas com a participação dos alunos, com ênfase na reflexão, questionamento e pesquisa.

Assim, é possível corroborar que a reflexão desenvolvida no diário de formação está colaborando para a transformação das práticas docentes, pois, à medida que investigam suas práticas, refletem sobre elas e tomam consciência dos seus fazeres. Essa reflexão é instituída como categoria formativa, por conseguinte, produz saberes da docência num processo investigativo que garante desenvolvimento profissional, pois, conforme Alarcão (2010), se o hábito da reflexão for adquirido desde a formação inicial, existem mais chances de o mesmo persistir na vida profissional.

\section{REFERÊNCIAS}

ALARCÃO, Isabel. Professores reflexivos em uma escola reflexiva. 7. ed. São Paulo: Cortez, 2010.

ÁLVAREZ, Carmen; MAROTO, José Luis San Fabián. Perspectivas para comprender la relación entre la teoría y la práctica en la formación del profesorado. Enseñanza \& Teaching, v.31, n.1, p. 23-42, 2013. Disponível em: http://revistas.usal.es/index.php/02125374/article/view/11603/12022. Acesso em: 20 abr. 2019.

ARAGÃO, Rosália M. R. de. Memórias de formação e docência: bases para pesquisa narrativa e bibliográfica. In: CHAVES, Sílvia Nogueira; BRITO, Maria dos Remédios de. (orgs.). Formação e docência: perspectivas da pesquisa narrativa e autobiográfica. Belém: CEJUP, 2011, p. 13-35.

CALLAI, Helena Copetti. O território do professor no espaço da aprendizagem. In: Anais do VI Seminário Internacional de Alfabetização e Educação Científica. Ijuí: UNIJUÍ, 1998.

CARR, Wilfred; KEMMIS, Stephen. Becoming critical: education, knowledge and action research. London: The Falmer Press, 1986. 
CARR, Wilfred; KEMMIS, Stephen. Teoria crítica de la enseñanza: investigación-acción en la formación del profesorado. Barcelona: Martinez Roca, 1988.

CONTRERAS, José Domingo. La investigación en la acción. Cuadernos de Pedagogia, $\mathrm{n}$. 224, Madrid: Morata, p. 7-31, 1994. Disponível em: https://dialnet.unirioja.es/ejemplar/3993. Acesso em: 20 abr. 2019

DEMO, Pedro. Educar pela Pesquisa. 4 ed. São Paulo: Autores Associados, 2000.

DOMINGUES, Gleyds Silva. Concepções de investigação-ação na formação inicial de professores. Orientadora: Roseli Pacheco Scnhetzler. 2007. 136 f. Dissertação (Programa de Pós-graduação em Educação) - Faculdade de Ciências Humanas, Universidade Metodista de Piracicaba, Piracicaba, 2007.

DORIGON, Thaisa Camargo; ROMANOWSKI, Joana Paulin. A reflexão em Dewey e Schön. Revista Intersaberes, Curitiba, v. 3, n. 5, p. 8-22, 2008. Disponível em: https://www.uninter.com/intersaberes/index.php/revista/issue/view/35. Acesso em: 20 abr. 2019

ELLIOT, Jhon. La investigación-acción en educación. 4 ed. Madri: Ed. Morata, 2000.

FILHO, Paulo de Sá et al. Teoria histórico-crítica: o caminho para uma Educação profissional e tecnológica Emancipadora. Revista Prática Docente. v. 3, n. 2, p. 768-780, 2018.

FRACALANZA, Hilário. O livro didático de Ciências no Brasil. Campinas: Editora Komedi, 2006.

FREIRE, Paulo. Pedagogia da Autonomia: saberes necessários para a prática educativa. 9.ed. Rio de Janeiro: Paz e Terra. 1998

GALIAZZI, Maria do Carmo. Educar pela Pesquisa: ambiente de formação de professores de ciências. Ijuí: Ed. UNIJUÍ, 2003.

GARCÍA, Carlos Marcelo. A formação de professores: novas perspectivas baseadas na investigação sobre o pensamento do professor. 1992. In: NÓVOA, Antonio. Os professores e a sua formação. 2. ed. Portugal: Ed. Porto, 1992.

GÓMEZ, Angel Pérez. O pensamento prático do professor: a formação do professor como profissional reflexivo. In: NÓVOA, Antonio. Os professores e a sua formação. 2 ed. Portugal: Ed. Porto, 1992.

GÜLLICH, Roque Ismael da Costa. Investigação-Formação-Ação em Ciências: um caminho para reconstruir a relação entre livro didático, o professor e o ensino. Curitiba: Editora Prismas Ltda, 2013.

IBIAPINA, Ivana Maria Lopes de Melo. Pesquisa colaborativa: investigação, formação e produção de conhecimentos. Brasília: Líber Livro Editora, 2008.

IMBERNÓN, Francisco. Formação continuada de professores. Porto Alegre: Artmed, 2010. 
KIEREPKA, Janice Silvana Novakowski; GÜLLICH, Roque Ismael da Costa. O desencadeamento do diálogo formativo pelo compartilhamento de narrativas em um contexto colaborativo de formação de professores. In: Anais [Seminário Internacional de Educação em Ciências]. Org: João Alberto da Silva et. al., Universidade Federal do Rio Grande FURG. São Leopoldo: Casa Leiria, 2014. Disponível em:

http://www.casaleiria.com.br/sintec3/sintec3.htm. Acesso em: 13 jun. 2019.

KRASILCHIK, Miriam. O professor e o currículo das ciências. São Paulo: EPU, 2004.

LÜDKE, Menga; ANDRÉ, Marli Eliza Dalmazo Afonso de. Pesquisa em educação: abordagens qualitativas. São Paulo: EPU, 2001.

MALDANER, Otavio Aloisio. A Formação do Professor Pesquisador. “a pesquisa do professor como prática de formação continuada.”. In: Anais [VI Seminário Internacional de Alfabetização e Educação Científica]. Unijuí, 1998.

MORAES, Roque. Ninguém se banha duas vezes no mesmo rio. Currículos em processo permanente de superação. In: MORAES, Roque; MANCUSO, Ronaldo. Educação em ciências: produção de currículos e formação de professores. Ijuí: Ed. UNIJUÍ, 2004. p.15-41.

MORAES, Roque. Educar pela Pesquisa: exercício de aprender a aprender. In: MORAES, Roque; LIMA, Valderez Maria do Rosário (orgs.). Pesquisa em sala de aula: Tendências para a educação em novos tempos. Porto Alegre: EDIPUCRS, 2002.

MORAES, Roque; GALIAZZI, Maria do Carmo; RAMOS, Maurivam Guntzel. Pesquisa em sala de aula: fundamentos e pressupostos. In: MORAES, Roque; LIMA, Valderez Maria do Rosário (orgs.). Pesquisa em sala de aula: Tendências para a educação em novos tempos. Porto Alegre: EDIPUCRS, 2002.

NÓVOA, Antonio. Formação de professores e profissão docente. In: NÓVOA, Antonio. Os professores e a sua formação. 2 ed. Portugal: Ed. Porto, 1992.

PIMENTA, Selma GarridoPesquisa-ação crítico-colaborativa: construindo seu significado a partir de experiências com a formação docente. Educação e Pesquisa. São Paulo, v. 31, n. 3, p. 521-539, 2005. Disponível em: http://www.scielo.br/pdf/ep/v31n3/a13v31n3.pdf. Acesso em: 08 abr. 2019

PORLÁN, Rafael; MARTÍN, José. EI diario del profesor: um recurso para investigación em el aula. Sevilla, Díada, 2001.

REIS, Pedro Rocha. As narrativas na formação de professores e na investigação em educação. Nuances: estudos sobre educação, v. 15, n. 16, p. 17-34, 2008. Disponível em:

http://revista.fct.unesp.br/index.php/Nuances/article/view/174. Acesso em: 08 abr. 2019.

ROSA, Maria Inês de Freitas Petrucci dos Santos. Investigação e ensino: articulações e possibilidades na formação de professores de ciências. Ijuí: Ed. Unijuí, 2004.

ROSA, Maria Inês de Freitas Petrucci dos Santos; SCHNETZLER, Roseli Pacheco. A investigação-ação na formação continuada de professores de ciências. Ciência e Educação, v. 9, n. 1, p. 27-39, 2003. http://dx.doi.org/10.1590/S1516-73132003000100003 Disponível 
em: http://www.scielo.br/scielo.php?script=sci_arttext\&pid=S151673132003000100003\&lng=pt\&tlng=pt. Acesso em: 08 abr. 2019.

SCHÖN, Donald. Formar professores como profissionais reflexivos. 1992. In: NÓVOA, Antonio. Os professores e a sua formação. 2. ed. Portugal: Ed. Porto, 1992.

SCHÖN, Donald. Educating the refective practitioner. San Francesco: Jossy- Bass Inc. Publishers, 1987.

SCHÖN, Donald. The reflective practitioner. San Francisco: Basic Books, 1983.

TARDIF, Maurice. Saberes Docentes e Formação Profissional. Petrópolis, RJ: Vozes, 2002.

TRIPP, David. Pesquisa-ação: uma introdução metodológica. Educação e Pesquisa. v. 31, n. 3, p. 443-446. 2005. Disponível em: http://www.scielo.br/pdf/\%0D/ep/v31n3/a09v31n3.pdf. Acesso em: 08 abr. 2019

VIGOTSKI, Lev Semyonovich. A construção do pensamento e da linguagem. Tradução Paulo Bezerra. São Paulo: Martins Fontes, (2001).

ZANON, Lenir Basso. Interações de licenciandos, formadores e professores na elaboração conceitual de prática docente: Módulos triádicos na licenciatura de Química. Orientadora: Roseli Pacheco Schnetzler. 2003. Tese (Doutorado em Educação)- Faculdade de Ciências Humanas, Universidade Metodista de Piracicaba, Piracicaba, 2003.

ZEICHNER, Kenneth. Uma análise crítica sobre a "reflexão" como conceito estruturante na formação docente. Educação e sociedade, Campinas, vol. 29, n. 103, p. 535-554, 2008. Disponível em: http://www.cedes.unicamp.br Acesso em: 08 abr. 2019.

Recebido em: 13 de junho de 2019. Aprovado em: 05 de novembro de 2019. 